\title{
Crossing geographical, legal and moral boundaries: the Belgian cigarette black market
}

T Vander Beken, J Janssens, K Verpoest, A Balcaen and F Vander Laenen

Tob. Control 2008;17:60-65

doi:10.1136/tc.2007.022749

Updated information and services can be found at:

http://tobaccocontrol.bmj.com/cgi/content/full/17/1/60

References

Rapid responses

Email alerting service

\section{These include:}

This article cites 15 articles, 5 of which can be accessed free at: http://tobaccocontrol.bmj.com/cgi/content/full/17/1/60\#BIBL

You can respond to this article at:

http://tobaccocontrol.bmj.com/cgi/eletter-submit/17/1/60

Receive free email alerts when new articles cite this article - sign up in the box at the top right corner of the article

Notes

To order reprints of this article go to:

http://journals.bmj.com/cgi/reprintform

To subscribe to Tobacco Control go to:

http://journals.bmj.com/subscriptions/ 


\title{
Crossing geographical, legal and moral boundaries: the Belgian cigarette black market
}

\author{
T Vander Beken, J Janssens, K Verpoest, A Balcaen, F Vander Laenen
}

Institute for International Research on Criminal Policy (IRCP), Ghent University, Ghent, Belgium

Correspondence to:

J Janssens, Academic assistant, Universiteitstraat 4, 9000 Gent, Ghent University, Institute for International Research on Criminal Policy (IRCP), Belgium; jelle.janssens@ugent.be

Received 12 July 2007 Accepted 6 November 2007

\section{ABSTRACT}

Objectives: To describe and analyse the cigarette smuggling trade in Belgium and its role in the international cigarette black market.

Design: Analysis of Belgian customs and prosecution files concerning the cigarette smuggling trade in the period 2000 to 2006 and interviews with law enforcement authorities and private tobacco industry.

Results: Analyses were made of the geographical aspects, the modus operandi and the participants of the cigarette smuggling trade in Belgium. Belgium is mainly a transit country. The cigarettes are transported via the fine-meshed Belgian highway network to the UK, which is often the destination country of the cigarettes. China is the most popular country of origin, especially for counterfeited cigarettes. In order to transport the cigarettes often use was made of legal transport companies and warehouses were frequently used to store the cigarettes. Many of the persons involved in the Belgian cigarette smuggling trade are strongly connected to legitimate business activities.

Conclusions: Belgium is an important transit country for cigarette smuggling to the UK. This study pictures the illicit tobacco trade as a complex, ambiguous phenomenon involving several legal and illegal participants whereby the transit of cigarettes across the licit/illicit divide is paralleled by the moral careers of those who smuggle them, not to mention those who consume them. From the legal world to the illegal and back again, this trade and its practitioners and customers blur the line between criminality and non-criminality. Dealing with this phenomenon therefore requires more than a strategy focusing on these lawbreakers alone.

Cigarette smuggling is an area of activity in which customers, traders and the industry are implicated in a blurring of moral as well as geographical boundaries. All the indications are that the scale of the trade is considerable and that prevention and enforcement have some way to go before they "make a difference". The problem is however recognised by the public sector and also by the industry concerned. Action by the public sector is motivated by the loss of tax incomes related to smuggling and also by concerns from law enforcement agencies that this form of smuggling may be linked with other forms of criminality within and surrounding the European Union, and the potential nexus with terrorism (see for example the EU Organised Crime Report 2005 (OCR), Crimorg 117, Brussels, 17 November 2005 and the EU Organised Crime Threat Assessment 2006 (OCTA), Crimorg 94, Enfopol 115). ${ }^{1}$ Irrespective of the role of the tobacco industry in the illicit tobacco trade, ${ }^{2}$ they now face losses running into hundreds of millions of Euros in income and have become reputationally compromised by the development of a parallel supply chain that is swamping and endangering legal distribution channels. ${ }^{3}$ The uncertain make-up of counterfeited cigarettes may pose risks to public health in addition to the known dangers of licit cigarettes. Faced with these issues-but also with a great degree of uncertainty over the forms taken by cigarette smuggling - both public and private actors are seeking insights into the forms of criminality involved and the conditions that facilitate them.

In past decades, considerable research has been conducted into the organisation of the legal and illegal cigarette markets. Cigarette smuggling has been described as a highly lucrative and somewhat complex ${ }^{2}$ result of actions (and non-actions) by the industry ${ }^{5-7}$ criminals $^{8}$ policy makers ${ }^{9-11}$ and enforcement agencies. ${ }^{12}$ The phenomenon has an explicit international dimension ${ }^{13}$ and follows specific patterns $s^{14}$ and routes ${ }^{15}$ yet it is influenced only to a limited extent by price and tax differentiations within the market. ${ }^{2}$

The scope of this paper is limited to an assessment of the Belgian role in the illicit cigarette trade. This country plays a pivotal role in the distribution sector within the European Union, because of its geographical location and also because its main port, Antwerp (one of the largest ports in the world), is also said to be an attractive operating base for smugglers. ${ }^{2}$ We address the following questions: what is the role of Belgium in the illicit cigarette trade? Who are the smugglers, and does their reality correspond with the one that is pictured in media and governmental reports? How do they transport their contraband, and what routes do they follow? Finally, what lessons can be drawn to contribute to preventive strategies, and more specifically, how could this information contribute to the development of a protocol on illicit tobacco trade?

\section{METHODS}

\section{Data collection}

The data used for this paper was collected during a study carried out for the European Commission in the context of a project called "Assessing Organised Crime: testing the Feasibility of a Common European Approach in a Case Study of the Cigarette Black Market in the EU" (project CIS8-CT-2004-501767 financed by the European Commission under the Sixth Framework programme, within the framework of the specific research and technological development programme "Integrating and strengthening the ERA"). As a partner in this European project, 
Ghent University undertook an analysis of 44 different Belgian customs (30) and public prosecution (14) files concerning the illegal cigarette trade in the period from 2000 to 2006. In Belgium there are no files specifically labelled as cigarette smuggling files. The investigators in charge of cigarette smuggling cases provided a list of all cases known to them. In order not to compromise ongoing investigations, access to 13 of the 27 prosecution cases was denied. Access was granted to all customs files.

After being granted access to the files, the files were studied at the different Public Prosecutor's offices or at the registry. Eleven interviews with law enforcement representatives were conducted and one with a private sector representative (British American Tobacco, London, UK). The interviews helped us to learn more about the Belgian cigarette black market and provided some background information that assisted us in orientating our focus and in sifting through the case files in a productive manner. In order to capture the variety of phenomenon under study, we opted for diversity in our selection of cases. We therefore included cases involving only cigarette smuggling, cases also involving other crimes, cases involving genuine cigarettes and counterfeits, cases involving both solo individuals and groups, and cases with both local and broader international dimensions. Concerning the timeframe, we focussed on the period from 2000 to 2006 (one case did start before the year 2000, but as this case was still pending and the suspects committed offences until 2003, the file was included in the case analysis; table 1 ). In total, we analysed 30 cases at the customs office and 14 at the Public Prosecutor's office. In those 44 case files, 251 persons were mentioned. Eight persons figured in more cases so, after correction of this double counting, 243 persons were identified in the files studied.

Generally, there are two avenues through which cigarettes are supplied to the black market: bootlegging, and large scale smuggling of brand-named or counterfeited cigarettes. ${ }^{16}$ While bootleggers actually pay excise taxes (while purchasing cigarettes in a country or region where taxes are low), large scale smugglers try to avoid excise taxes entirely. ${ }^{16}$ Bootlegging is said to be encouraged by substantial differences in the price of tobacco products between neighbouring countries or between neighbouring states or provinces. Bootlegging is often organised by "gangs", but would not require huge investment as cigarettes are transported by car or van. As profits increase when larger amounts of cigarettes are being sold, bootleggers attempt to maximise the number of cigarettes transported. Large-scale smugglers strive to transport as many cigarettes as possible at once by using trucks or containers. This might require a higher level of investment and a more complex and well organised network. ${ }^{17}$

\section{RESULTS}

\section{Belgium as a transit country in the heart of Europe}

When analysing the case files, it is significant that most contraband was not meant to be sold on the Belgian market, but was meant for onward transport, which is encouraged by geographical and policy factors. Belgium is situated in the heart of Europe and is located on the smuggling routes from east to west and south to north. Moreover, being close to the UK,
Belgium is a very attractive country for cigarette smugglers. Consequently, warehouses in Belgium are often used to stock illegal cigarettes. As for policy, penalties in Belgium are rather low, and this may contribute to this county's frequent involvement in cigarette smuggling. For fiscal fraud, a prison sentence of maximum 1 year can be imposed in Belgium, while in other countries (eg, Italy), a person can receive up to 15 years imprisonment (information from CDGEFID (directory of the fight against economic and financial crime), the special branch of the Belgian Federal Police responsible for investigations concerning cigarette smuggling, 22 April 2004).

\section{The nature of the contraband}

Smuggled cigarettes are mostly not related to "home" brands originating from Southern European countries, but are related to expensive international brands. ${ }^{2}$ During the case file analysis, a total of 17 brands could be identified: Superkings, Silk Cut, Regal, Lambert \& Butler, Sovereign, Marlboro, Golden Virginia, Drum, Winston, Carlton, Fame, Belga, Bastos, Benson \& Hedges, Raquel, Dorchester, Mayfair and L\&M. Seven of them belong to the top 10 of most popular brands in the UK (table 2). ${ }^{18}$ The most recurrent brands in the case files are: Regal (23 times), Superkings (18 times), Sovereign (15 times), Marlboro (14 times) and Benson \& Hedges (7 times).

Just 5 out of 44 cases were concerned with cigarettes with valid fiscal seals. In four cases, counterfeited cigarettes were smuggled together with genuine cigarettes. In 15 cases, the files did not indicate whether the cigarettes were counterfeit or not. This leaves 20 cases where all of the cigarettes were described as counterfeited (table 3).

These findings correspond with findings from the National Customs Office. During the interviews, it was repeatedly mentioned that the market share of counterfeit cigarettes has increased in recent years and will probably continue to do so. ${ }^{19}$ No one knows which and to what extent substances more toxic than in branded cigarettes are present in counterfeits. Most counterfeited cigarettes originate from non-EU countries such as China and Russia. In all cases with China as country of origin, the counterfeited cigarettes carried the brand Marlboro.

\section{Profiling the smuggler}

Until today, little information has been published on the individuals involved in cigarette black market activities. ${ }^{20}$ van Duyne and von Lampe conducted research concerning the indigenous cigarette black market in respectively The Netherlands and Germany. Both also investigated smuggler profiles. ${ }^{14} 15$

Since Belgium can be characterised as a transit country, it appears to have more in common with the situation in The Netherlands (primarily a transit country) than with the state of affairs in Germany (which is often the final destination). In the 44 cases we studied, of the 243 persons, 10 were women. These women appear to perform various functions within the collective: car owner, company owner, smuggler; though most were subsidiary functions. As for age, it is commonly observed that "petty" or "volume" crimes such as theft peak between adolescence and adulthood and then begin to decline. ${ }^{21}$ For

Table 1 Numbers of case files studied, by years in which cases started

\begin{tabular}{lllllllll}
\hline Year & $\mathbf{1 9 9 7 ^ { * }}$ & $\mathbf{2 0 0 0}$ & $\mathbf{2 0 0 1}$ & $\mathbf{2 0 0 2}$ & $\mathbf{2 0 0 3}$ & $\mathbf{2 0 0 4}$ & $\mathbf{2 0 0 5}$ & $\mathbf{2 0 0 6}$ \\
\hline $\mathrm{n}$ & 1 & 3 & 2 & 6 & 10 & 10 & 10 & 2
\end{tabular}

* One case did start before the year 2000, but as this case was still pending and the suspects committed further offences until 2003, the file was included in the case analysis. 
Table 2 Top 10 UK cigarette brands, $2004^{18}$

\begin{tabular}{llll}
\hline Rank & Brand name & Share of UK cigarette market (\%) & Manufacturer \\
\hline 1 & Lambert \& Butler KS & 13.5 & Imperial Tobacco \\
2 & Benson \& Hedges Gold & 7.3 & Gallaher \\
3 & Mayfair King Size & 7.1 & Gallaher \\
4 & Richmond Superkings & 6.6 & Imperial Tobacco \\
5 & Richmond King Size & 4.9 & Imperial Tobacco \\
6 & Marlboro Gold King Size & 4.4 & Philip Morris \\
7 & Regal KS & 3.5 & Imperial Tobacco \\
8 & Royals King Size Red & 3.4 & British American Tobacco \\
9 & Superkings & 3.3 & Imperial Tobacco \\
10 & Silk Cut Purple & 3.2 & Gallaher \\
\hline
\end{tabular}

serious economic crimes, however, which are more demanding, the peak lies in another modal age class. Several examples of this can be found in the literature. ${ }^{22} 23$ This also appears to be true for cigarette smugglers. The modal age of those in the files studied is between 35 and 45 years, the vast majority of the suspects being 35 years or older. A total of 59 people were older than 45 , while only $14 \%$ were younger than 30 . The average age was 40 ranging, from 18 to 73 (table 4). These results are very similar to van Duyne's findings.

Law enforcement agencies, policymakers, the media and the general public show a lot of interest in criminal networks consisting of individuals connected with each other through family loyalty ${ }^{24}$ or the presence of a "godfather" figure. ${ }^{25} \mathrm{~A}$ number of elements often referred to are nationality, residence, family ties, division of tasks and the existence of a criminal record. Our analysis of these elements does not confirm this stereotypical "mafia"-like picture.

As regards the nationality of the smugglers, the majority of the suspects (94) were of Belgian nationality. The nationality of 51 individuals could not be established with certainty on the basis of the file information. The other 98 non-Belgian persons covered 23 nationalities. Three nationalities were predominant: 19\% were British, 17\% Dutch and 12\% Polish. The frequent occurrence of Polish and Dutch suspects can be explained by the fact that The Netherlands and Poland are attractive transit countries. The predominance of British offenders can be explained by the fact that the UK is very often the end customer. ${ }^{14}{ }^{15}$

Concerning possible family ties, it appeared that relatives were involved in only eight cases. Two of these cases concerned twin brothers. Other cases involved relationships between mother and daughter, mother and son, father and son, husband and wife and between brothers. This implies either that family is not greatly involved in cigarette smuggling, or that the investigations may have missed information on this aspect; we have no view on this.

Although the cigarette smugglers are clearly involved in criminal activities and maintain contacts with others who behave similarly, according to the files they do not often appear to have a pevious criminal record. However, one should be cautious about drawing conclusions from this. The absence of a criminal past in the files may indicate a gap in data collection and processing. According to

Table 3 Authenticity

\begin{tabular}{lcc}
\hline Authenticity & n & Percentage \\
\hline Genuine and counterfeited cigarettes & 4 & $9.1 \%$ \\
Genuine cigarettes & 5 & $11.4 \%$ \\
Counterfeited cigarettes & 20 & $45.4 \%$ \\
Unknown & 15 & $34.1 \%$ \\
Total & 44 & $100 \%$ \\
\hline
\end{tabular}

other sources, people involved in smuggling activities do have criminal backgrounds, and the first time that a person appears in the files of an investigation or prosecution agency would not necessarily correspond with their first offence. ${ }^{26}$

Because of the type of illegal activities they undertake, cigarette smugglers are often obliged to form a "group" and work together with other criminals. ${ }^{27}$ In his study of the Dutch cigarette black market, van Duyne distinguishes local traders, international traders, intermediaries and professional transporters. ${ }^{14}$ Local traders are entrepreneurs with no or limited administrative skills and no professional experience in international trading. The international traders, by contrast, operate within multinational networks. This requires a minimum level of skill or access to other professionals for the correct handling of the containers or trucks at customs. Intermediaries are, according to van Duyne, not a specific group of individuals, but focal points of networks consisting of local traders as well as other, smaller intermediaries. They get the merchandise on the market and are used to having assistants for driving delivery vans, escort or storing the contraband, while these assistants are also trading for themselves. The professional transporters are legitimate licensed firms or one-man enterprises, mainly involved in cross-border transporting of the contraband. Based on the aforementioned classification, the extraction seen in table 5 can be made.

The use of violence appears to be minimal, which confirms van Duyne's conclusions. ${ }^{14}$ Of course there are situations in which threats are expressed, but real violence is rare. In the case file analysis there was only one case in which there was a suspicion of a murder in relation to the smuggling of cigarettes. During the interviews, police officers surmised that the lack of violence could also be related to the minimal control that is directed towards this activity; consequently, smugglers have no real reason or need to use violence. ${ }^{26}$

\section{Transport, routes and entrepreneurial involvement}

Cigarettes are not heavy, but they are voluminous. In Belgium, cigarettes are often smuggled via road transport, by trucks and ordinary passenger cars (ie, non-transport specialised). ${ }^{28}$ Bootleggers frequently use cars or vans to get their cigarettes abroad. Of course, when a criminal group is involved, cars may be used to guide trucks to warehouses or to observe police actions. In 11 cases in the files studied, cars were used. However, the most current means of transportation via the road is by truck and/or trailer. This occurred in 32 out of the 44 cases. The use of a container occurred 13 times and 8 times a ship was used. In the latter cases, the seizure took place at the port in Antwerp where the containers would then be further transported by truck. In some cases multiple means of transportation were used. Table 6 shows a breakdown of transport modes. 
Table 4 Age

\begin{tabular}{lcc}
\hline Age classes & $\mathbf{n}$ & Percentage \\
\hline$>45$ & 59 & $24.3 \%$ \\
$35-45$ & 74 & $30.4 \%$ \\
$30-34$ & 32 & $13.2 \%$ \\
$<30$ & 34 & $14.0 \%$ \\
Unknown & 44 & $18.1 \%$ \\
Total & 243 & $100 \%$ \\
\hline
\end{tabular}

Van Duyne ${ }^{14}$ and von Lampe ${ }^{15}$ found that there is an interaction between cigarette crime-entrepreneurs and legitimate entrepreneurs. Analysis of the case files revealed the involvement of as many as 152 legal businesses. In only five cases were no legal enterprises apparently involved. Based on the data presented in the files, it was not possible to ascertain the nature of involvement of the implicated enterprises.

The strong interaction between legal companies and the illegal entrepreneurs is striking. van Duyne concluded that the complicity of legal enterprises in cigarette smuggling activities points to the prevalence of a kind of moral absent-mindedness where people perceive cigarette smuggling as a "lesser" crime. ${ }^{14}$ The private tobacco sector, public officials, private entities and consumers do not feel that they are taking part in an essentially criminal business.

In 28 cases, use was made of legal transport companies. In all cases the transport companies were set up as legal companies and undertook, besides their fraudulent actions, legal transport work. Truck drivers were approached at night at parking places and were asked if they were willing to transport cigarettes to the UK along with their legal cargo in exchange for remuneration.

Since Belgium is a transit country, a lot of cigarettes are imported to warehouses. ${ }^{2}$ From the case files it appears that in 25 cases, warehouses were being used to store the cigarettes awaiting further transport. According to the literature, a lot of warehouses located around the port of Antwerp serve as stockpiling locations for contraband cigarettes. $^{2}$

Getting hold of means of transportation is one thing, hiding the cigarettes is another. A cover load can exist on paper only, which means that the documents accompanying the transport state that certain goods are stored in a truck or container, while in reality there are just cigarettes. However, the most frequent modus operandi used by the smugglers (in 30 cases of those studied) is to create a "wall" of licit merchandise in the transport vehicle, for example packages of cotton, with cigarettes being hidden behind. Another modus operandi, though only mentioned in three cases, is concealing the cigarettes in secret compartments; the cigarettes are hidden in the cover load or elsehwhere in the transport vehicle. We came across some other techniques such as the use of aliaes, falsification of documents, or setting up of sham companies for money laundering, but these appeared infrequently in the case files. Compared to techniques used in drug trafficking, the methods of concealment used seem to be less sophisticated. ${ }^{29}$

Since transportation is crucial to the success of the cigarette smuggling, it is no surprise that the vast majority of suspects $(n=73)$ are employed as either truck drivers $(n=24)$ or business managers, employees at transport companies or shipping agencies, lessees of warehouses etc. $(n=49)$. Most of them knowingly and willingly cooperate with the smuggling activities, according to the prosecution and customs files. Study of the files shows that the truck drivers first of all engage in legal activities, but in addition also undertake one or more illegal transport jobs. The other group
Table 5 Task division

\begin{tabular}{lrc}
\hline Task & \multicolumn{1}{c}{$\mathbf{n}$} & Percentage \\
\hline Main local traders & 7 & $6.5 \%$ \\
International traders & 31 & $29.0 \%$ \\
Intermediaries & 42 & $39.3 \%$ \\
Professional transporters & 27 & $25.2 \%$ \\
Total (known) & 107 & $100 \%$ \\
Known & $\mathbf{1 0 7}$ & $\mathbf{4 4 \%}$ \\
Unknown & $\mathbf{1 3 6}$ & $\mathbf{5 6 \%}$ \\
Total & $\mathbf{2 4 3}$ & $\mathbf{1 0 0 \%}$ \\
\hline
\end{tabular}

mainly supplies logistic support, such as renting out depots. Some offenders have official approval as managers of customs warehouses, and therefore on paper can legally store and forward goods - but in reality set up smuggling networks.

In 17 cases, the origin of the cigarettes was a non-European country. In nine of those cases, the cigarettes originated from China. Other popular countries of origin are the United Arab Emirates and the ex-Soviet Union. In 22 cases, the cigarettes originated from a European country. Spain was, in the analysed cases, the most popular European country of origin of the cigarettes. In six cases there was no information on their provenance.

Belgium is often cited as a transit country, and our case file study naturally reflects this being drawn from Belgian sources. In 29 cases Belgium is mentioned as a transit country. In seven cases, the countries that the cigarettes passed through on route is not mentioned. From the other cases, France, Germany and The Netherlands are the most frequently mentioned countries.

The main smuggling route identified in the 44 cases is the route from east to west. Only in four cases did cigarettes originate from the south, destined for the north. The UK seems to be a very popular final destination ( 25 cases). This percentage is probably an understatement, as the destination country is frequently not mentioned in the files. However, as in those files the cigarettes are British brand-named cigarettes, it is reasonable to suspect that they are destined for the British market too.

\section{CONCLUSIONS}

An effective strategy requires one to know with what and with whom one is dealing. Based on case files of Belgian investigation and prosecution agencies, it can be concluded that Belgium mainly functions as a transit country for cigarette smuggling. In the vast majority of cases, the UK is the destination country for the cigarettes. This is no doubt the reason why most of the smuggled cigarettes are British brands. China is the most popular country of origin, especially for counterfeited cigarettes.

In the case files studied, several modus operandi used by the criminals are mentioned. In almost all the cases, cover loads are used during the transport of the cigarettes. The cigarettes are mostly transported via the fine-meshed Belgian highway network. Large-scale smugglers need larger means of transportation than bootleggers, and therefore often use trucks or containers. The vehicles used for the transportation are in most cases the property of legal companies involved in the smuggling activities. Very often, warehouses are used to store the cigarettes. In short, cigarette smuggling shows various links with the legal businesses world.

A picture can be drawn of those typically involved in the cigarette black market in Belgium. It concerns a man of 40 years old with Belgian nationality. He lives legally in Belgium and is probably involved in large scale smuggling activities as an 
Table 6 Means of transportation

\begin{tabular}{lcc}
\hline Means of transportation & $\mathbf{n}$ & Percentage \\
\hline Passenger cars & 11 & $17.2 \%$ \\
Truck/trailer & 32 & $50.0 \%$ \\
Container & 13 & $20.3 \%$ \\
Ship & 8 & $12.5 \%$ \\
Total & 64 & $100 \%$ \\
\hline
\end{tabular}

intermediary. There is not much information in the files on his ethnicity and economic and social background, and there is little indication that his relatives are involved in these activities. Both this study and the Dutch study show that the individuals involved in cigarette smuggling appear to have a legitimate business background, which may point to a certain prevalence of some sort of moral absent-mindedness in which people perceive cigarette smuggling as a "lesser" crime.

These bare facts are the "where", "how" and "who" of the cigarette smuggling trade in Belgium, as known to the law enforcement and prosecution agencies (or at least, as described in the files made available to the researchers). We also know the "why", which is simple and readily understandable financial motivation, ready markets, and relatively low levels of law enforcement and penalties (compared with drug smuggling, for example). Although countermeasures have not been the focus of this study, our results may bring additional perspectives to policy discussions on cigarette smuggling.

The issue of reduction (or rather "elimination") of the illegal tobacco trade has, among others, been raised by the World Health Organization. Article 15 of the WHO Framework Convention on Tobacco Control (FCTC) deals with illicit trade in tobacco products and urges the parties signing to undertake action in order to eliminate illicit trade in tobacco products. This article, however, is considered to be too unspecific to be fully effective, therefore needing a supplementary protocol. ${ }^{30}$ In the meantime, an expert group drafted a template for a protocol recommending certain provisions to WHO FCTC article $15 .{ }^{31}$ Some of the provisions are: control of the supply chain through licensing, anti-money-laundering measures, a tracking/tracing system to allow authorities to keep records of all shipments, security and preventive measures (remains vague except for civil penalties for manufacturers who do not properly control their supply chain), enhanced law enforcement capacity (sufficient trained officers, intelligence-controlled policing, state of the art detection and surveillance technologies, training programmes), penalisation, confiscations, seizure of assets, special enforcement techniques, information sharing etc.

By doing this, the expert group seems to have chosen for a "law and order" approach in tackling the illegal tobacco trade, concentrating on technical preventive measures, data collection and sharing, criminalising and penalising. Without doubt, these aspects fit in a global strategy against the illicit tobacco trade. The results of our empirical study, however, can be used as an argument to opt for a more comprehensive approach. According to our findings, cigarette smuggling is not a crime phenomenon that can be located in the "underworld", but has many connections to the legitimate business and legal world. In such cases, counterstrategies would best go beyond mere repressive actions and include general and selective preventive $e^{32}$ aspects, with a broader spectrum. ${ }^{33}$ One could include general prevention actions concentrating, for example, on spatial aspects of parking spaces for truck drivers (the place where many legal and illegal activities meet), or on public awareness raising awareness

\section{What this paper adds}

In past decades, considerable research has been conducted into the organisation of the legal and illegal cigarette market. Cigarette smuggling can be described as a highly lucrative and somewhat complex ${ }^{2}$ result of actions and non-actions by the industry, ${ }^{5-7}$ criminals, ${ }^{8}$ policy makers ${ }^{9-11}$ and enforcement agencies. ${ }^{12}$ The phenomenon has an explicit international dimension ${ }^{13}$ and follows specific patterns ${ }^{14}$ and routes, ${ }^{15}$ yet it is influenced only to a limited extent by price and tax differentiations within the market. ${ }^{2}$ This paper adds specific and detailed information on offenders, smuggle routes and modus operandi. Although focused on the Belgian situation, which has not been studied previously, the analysis also deepens existing knowledge on cigarette smuggling on a larger geographical scale. Furthermore, the results introduce additional elements into the discussion on development of a policy to tackle the illegal tobacco trade.

of the consequences of purchasing smuggled cigarettes (buyers of smuggled cigarettes do not feel engaged with "real crime" at present). At a selective prevention level, target hardening measures focusing on the detection of risk offenders or potential crime-facilitating opportunities are proposed in the draft protocol. Given the legal/illegal nexus, one could go further on this point and use the results of vulnerability studies of relevant economic sectors (eg, the transport sector), to detect weak points in the economic environment that might be exploited by criminals active in cigarette smuggling (eg, the problems related to recruitment of lorry drivers, financial pressures on small transport companies etc.). ${ }^{34}$

In summary, our findings are that the Belgian cigarette smuggling sphere is a complex, ambiguous phenomenon involving several legal and illegal participants, and that the transit of cigarettes across the licit/illicit divide is paralleled by the moral careers of those who smuggle the goods, not to mention those who consume them. From the legal world to the illegal and back again, this trade and its practitioners and customers blur the line between criminality and non-criminality, adding to the perception that some laws are "ok" to be broken.

Acknowledgements: We would like to acknowledge the financial support of the European Commission.

Funding: Funding was received from the European Commission

Competing interests: None.

\section{REFERENCES}

1. US General Accounting Office. Terrorist Financing: U.S. agencies should systematically assess terrorists' use of alternative financing mechanisms. Washington, DC: US General Accounting Office, 2003. http://www.gao.gov/new.items/d04163.pdf (accessed 10 September 2007).

2. Joossens L, Raw M. Cigarette smuggling in Europe: who really benefits? Tob Control 1998; 7:66-71.

3. Galbraith J, Kaiserman M. Taxation, smuggling and demand for cigarettes in Canada: evidence from time-series data. J Health Econ 1997;16:287-301.

4. Wiltshire S, Bancroft A, Amos A, et al. They're doing people a service - qualitative study of smoking, smuggling, and social deprivation. BMJ 2001;323:203-7.

5. Saba RP, Beard TR, Ekelund RB, et al. The demand for cigarette smuggling. Econ Inq 1995;33:189-202.

6. Beare ME. Organized corporate criminality: corporate complicity in tobacco smuggling. In: Beare ME, ed. Critical reflections on transnational organized crime: money laundering and corruption. Toronto: University of Toronto, 2003:183-206.

7. Collin J, Legresley E, Mackenzie R, et al. Complicity in contraband: British American Tobacco and cigarette smuggling in Asia. Tob Control 2004;13:104-11.

8. Joossens L, Raw M. Turning off the tap: the real solution to cigarette smuggling. Int J Tuberc Lung Dis 2003;7:214-22. 
9. Licari MJ, Meier KJ. Regulation and signalling: when a tax is not just a tax. J Polit 2000;62:875-85

10. Goel RK. Cigarette demand in Canada and the US-Canadian cigarette smuggling. Appl Econ Lett 2004;11:537-40.

11. Wen CP, Peterson RA, Cheng TYD, et al. Paradoxical increase in cigarette smuggling after the market opening in Taiwan. Tob Control 2006:15:160-5.

12. Griffith H. Smoking guns: European cigarette smuggling in the 1990s. Global Crime 2004:6:185-200.

13. Coats RM. A note on estimating cross-border effects of state cigarette taxes. Nat/ Tax J 1995; 48:573-84.

14. van Duyne PC. Organizing cigarette smuggling and policy making, ending up in smoke. Crime Law Soc Change 2003;39:285-317.

15. von Lampe K. Explaining the emergence of the cigarette black market in Germany. In: van Duyne PC, von Lampe K, van Dijck M, et al, eds. The organized crime economy: managing markets in Europe. Nijmegen: Wolff Legal Publishers 2005:209-29.

16. Hornsby R, Hobbs D. A zone of ambiguity: the political economy of cigarette bootlegging. Br J Criminol 2007;47:551-71.

17. Joossens L. How to combat tobacco smuggling through the WHO Framework Convention on Tobacco Control. In Proceedings of the WHO Second World Conference, 3-7 December 2001, Durban: International Chamber of Commerce.

18. Action on smoking and health. The UK tobacco industry. http://ddash.org.uk/html/ factsheets/html/fact18.html (accessed 11 December 2007).

19. National Customs Office. Interview with NCO representative. 14 February 2006.

20. Von Lampe K. The cigarette black market in Germany and the United Kingdom. $J$ Financ Crime 2006;13:235-54.

21. Fagan $\mathbf{A}$, Western J. Escalation and deceleration of offending behaviours from adolescence to early adulthood. Aust NZ J Criminol 2005;38:59-76.

22. Strong S. Whitewash: Pablo Escobar and the cocaine wars. London: Pan Books, 1996.
23. Fry C. Doing the business: the mafia ethic and the spirit of capitalism. London: Verso, 1986.

24. Arlacchi P. Mafia business: the mafia ethic and the spirit of capitalism. London: Verso, 1986.

25. Gambetta D. The Sicilian mafia: the business of private protection. Cambridge, Massachusetts: Harvard University Press, 1993.

26. CDGEFID. Interview with Belgian police. 17 April 2004.

27. Junninen M. Adventurers and risk-takers: Finnish professional criminals and their organisations in the 1990s cross-border criminality. Helsinki: Heuni, 2006.

28. Council of Europe. Organised Crime Situation Report 2005: Focus on the threat of economic crime. Strasbourg: Octopus Programme, 2005.

29. US Drug Enforcement Agency. Drug trafficking in the United States. Washington, DC: DEA, 2007. http://www.dea.gov/pubs/state factsheets.html (accessed 05 October 2007).

30. WHO FCTC. FCTC COP-1 briefing paper. http://fcatc.org/docs/documents/ FCAbp3.pdf (accessed 10 September 2007).

31. WHO FCTC. Elaboration of a template for a protocol on illicit trade in tobacco products. http://www.who.int/gb/fctc/PDF/cop2/FCTC COP2 9-en.pdf (accessed 10 September 2007)

32. Pease K. Crime reduction. In: Maguire M, Morgan R, Reiner R, eds. The Oxford handbook of criminology. New York: Oxford University Press, 2002:948-79.

33. European Commission. Tobacco or health in the European Union: past, present and future. Strasbourg: The Aspect Consortium, 2004. http://ec.europa.eu/health/ ph determinants/life style/Tobacco/Documents/tobacco exs en.pdf (accessed 05 Oct 2007).

34. Vander Beken T, Verpoest K, Bucquoye A, et al. The vulnerability of economic sectors to (organized) crime: the case of the European road freight transport sector. In: van Duyne PC, Von Lampe K, van Dijck M, et al., eds. The organized crime economy. Managing markets in Europe. Nijmegen: Wolff Legal Publishers, 2005:19-41.

The Lighter Side

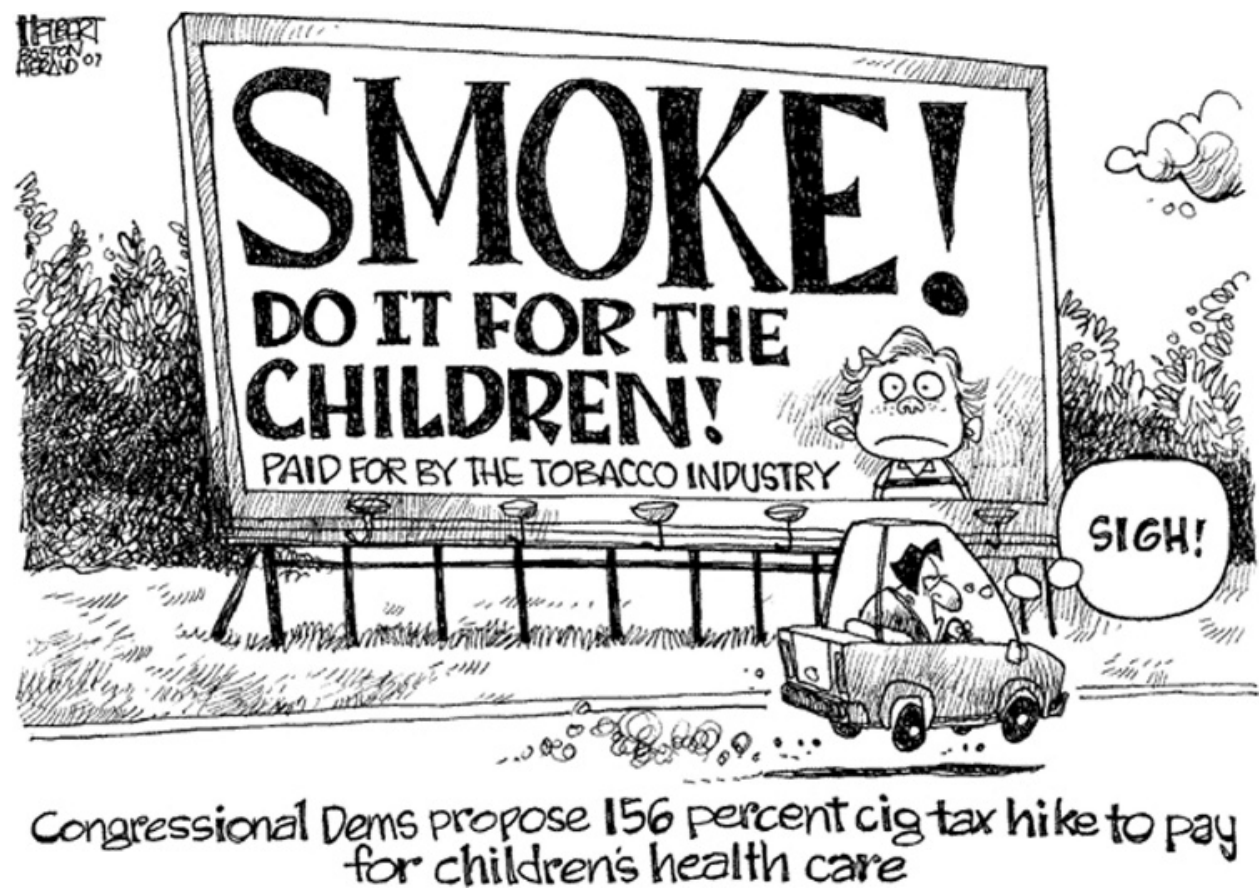

Jerry Holbert: (c) Boston Herald/Dist. by Newspaper Enterprise Association, Inc. 